\title{
Anti-inflammatory effects of Fagopyrum cymosum administered as a potential drug for ulcerative colitis
}

\author{
FEI GE ${ }^{1,2}$, SHILIN ZHU ${ }^{1}$, LINA LIU $^{3}$, JING YAN ${ }^{2}$, YU JI ${ }^{1}$ and ZHIGUANG SUN ${ }^{2}$ \\ ${ }^{1}$ Department of Gastroenterology, Haian Hospital of Traditional Chinese Medicine Affiliated to Nanjing University of \\ Chinese Medicine, Haian, Jiangsu 226600; ${ }^{2}$ First College of Clinical Medicine, Nanjing University of Chinese Medicine; \\ ${ }^{3}$ Department of Liver Disease, The Affiliated Hospital of Nanjing University of Chinese Medicine, \\ Nanjing, Jiangsu 210029, P.R. China
}

Received October 20, 2016; Accepted June 29, 2017

DOI: $10.3892 / \mathrm{etm} .2017 .5153$

\begin{abstract}
Fagopyrum cymosum (Trev.) Meisn (Fag), which belongs to the Polygonaceae family, has been widely used to treat inflammatory diseases. Previous studies have revealed that Fag components exhibit anti-inflammatory activities; however, their potential use in treating inflammatory bowel disease (IBD) has not been explored. In the present study, mice with 2,4,6-trinitrobenzenesulfonic acid (TNBS)-induced colitis were used as a model of IBD. Fag extract was orally administered for 3 days following the induction of colitis and the conventional drug, salicylazosulfapyridine (SASP), was used as a control. The results revealed that Fag significantly ameliorated TNBS-induced body weight loss and colonic shortening in mice $(\mathrm{P}<0.05)$. Furthermore, Fag suppressed levels of proinflammatory cytokines and reduced macrophage infiltration into colonic tissues $(\mathrm{P}<0.05)$. To further verify the anti-inflammatory effects of Fag at the molecular level, a murine macrophage cell line, Raw264.7, was used. Nuclear translocation of nuclear factor (NF) $-\kappa B$ p65 and the phosphorylation of inhibitor of $N F-\kappa B$ (IкB) were assessed using western blotting. The results demonstrated that Fag inhibited the production of proinflammatory cytokines via inhibiting NF- $\kappa \mathrm{B}$ p65 nuclear translocation and I $\mathrm{B}$ phosphorylation $(\mathrm{P}<0.05)$. Furthermore, the clinical study results revealed that Fag had significantly fewer side effects $(\mathrm{P}<0.05)$ and served as a better anti-inflammatory drug for ulcerative colitis compared with SASP.
\end{abstract}

\section{Introduction}

Inflammatory bowel disease (IBD) is characterized by chronic intestinal inflammation and is predominantly comprised

Correspondence to: Professor Zhiguang Sun, First College of Clinical Medicine, Nanjing University of Chinese Medicine, 138 Xianlin Road, Nanjing, Jiangsu 210029, P.R. China

E-mail:pr_zhiguangsun@163.com

Key words: Fagopyrum cymosum, colitis, 2,4,6-trinitrobenzene sulfonic acid inflammatory bowel disease of Crohn's disease (CD) and ulcerative colitis (UC) $(1,2)$. Approximately 3.6 million people are affected by IBD in the USA and Europe (2), and the number of patients with IBD in Asia has increased in recent years $(3,4)$. Although the exact etiology of IBD remains unknown, it has been reported that dietary habits, environmental factors, genetic susceptibility and infectious microbes may contribute to its development (5-8). At the molecular level, the pathogenesis of IBD involves an imbalance between proinflammatory cytokines, including tumor necrosis factor- $\alpha$ (TNF- $\alpha)$, interferon- $\gamma$ (IFN- $\gamma)$, interleukin (IL)-1 $\beta$, IL-6 and IL-12, and anti-inflammatory cytokines, including IL-4, IL-10 and IL-11 (9-11). As one of the most important regulators of proinflammatory gene expression, nuclear factor (NF) $-\kappa B$ serves several functions (12). In the cytoplasm, it exists in a stable complex form with inhibitory $\kappa \mathrm{B}(\mathrm{I} \kappa \mathrm{B})$. The NF- $\kappa \mathrm{B}-\mathrm{I} \kappa \mathrm{B}$ complex is disrupted by the phosphorylation of $\mathrm{I} \kappa \mathrm{B}$, and $\mathrm{NF}-\kappa \mathrm{B}$ is subsequently translocated to the nucleus and bound to DNA binding sites, which inducesthe transcription of target genes associated with inflammatory responses (13). Attenuating the activity of $\mathrm{NF}-\kappa \mathrm{B}$ has been used to treat a variety of immune disorders, including autoimmune and inflammatory diseases (14).

Proinflammatory cytokines, including IL-1, IL-6, and TNF- $\alpha$, are overexpressed in patients with IBD (12). Furthermore, a large population of infiltrated macrophages, which release inflammatory mediators including histamine, prostaglandin E2, nitric oxide and reactive oxygen species, may be detected in the patients' mucosa $(3,4)$. Macrophages also secrete proteases that damage tissue by degrading the extracellular matrix (14). Immunoregulation of active macrophages may therefore be an efficient treatment for IBD (15).

It has been reported that limiting colonic inflammation via anti-inflammatory agents may reduce the risk of developing UC-associated cancer (2). Various anti-inflammatory agents, including 5-aminosalic acid, corticosteroids and immunosuppressive agents, are widely used to treat IBD $(14,16,17)$. However, the serious side effects (including weight gain, osteoporosis, nausea and poor immunity) and high recrudescence rates of these agents limit their clinical applications (18). The conventional drug salicylazosulfapyridine (SASP) has been reported to induce chromosome aberrations and sister 
chromatid exchanges (19). Novel therapies and alternative medicines are therefore urgently needed. Herbal medicines have potential as treatments for IBD due to their low toxicity profiles and high patient compliance (7).

Fagopyrum cymosum (Trev.) Meisn (Fag), which is a herbal rhizome of the Polygonaceae family (20), and buckwheat species have been widely used to treat bacterial dysentery, lung disease (21), irritable bowel syndrome (IBS) and rheumatism (22-25). Previous chemical studies have revealed that Fag rhizomes contain compounds that are effective for the treatment of inflammatory disease, including phenolics, flavonoids, $\beta$-sitosterol, hecogenin, $p$-coumaric acid, ferulic acid, luteolin, dimericprocyanidin, glutinone, protocatechuic acid, epicatechin and shakuchirin $(20,21,26)$.

A previous study demonstrated that Fag is able to ameliorate hyperalgesia in rats with IBS (25). The hypothesis is that Fag reduces intestinal inflammation and enhances the function of mucosal epithelium via regulating the structure and function of tight junctions. To the best of our knowledge, the therapeutic effects of Fag on IBD have not previously been explored. In the present study, a 2,4,6-trinitrobenzenesulfonic acid (TNBS)-induced model of acute murine colitis was used to assess the therapeutic effects of Fag extract on IBD. To further investigate the anti-inflammatory effects of Fag at the molecular level, the phosphorylation of IкB and the nuclear concentration of NF- $\mathrm{\kappa B}$ were measured in lipopolysaccharide (LPS)-induced RAW264.7 macrophages in vitro.

\section{Materials and methods}

Plant materials and reagents. Fagopyrum cymosum was purchased from Jiangsu Traffic Hospital (Nanjing, China). All samples were identified by Dr Shengjin Liu (Department of Medicinal Plants, Nanjing University of Chinese Medicine, Nanjing, China). TNBS was obtained from Sigma-Aldrich (Merck KGaA, Darmstadt, Germany). SASP was supplied by Aladdin Shanghai Biochemical Technology Co., Ltd. (Shanghai, China). LPS was purchased from Sigma-Aldrich (Merck KGaA).

Extraction of Fag. Fag was extracted twice $(100 \mathrm{~g}$ in $800 \mathrm{ml}$ $50 \%$ ethanol) by conventional refluxing for $2 \mathrm{~h}$. The extracts were combined, filtered and concentrated under reduced pressure in a vacuum at $60^{\circ} \mathrm{C}$ to form a residue $(9.48 \mathrm{~g})$. The residue was resolved in $0.5 \%$ sodium carboxyl methylcellulose (Sigma-Aldrich; Merck KGaA) for animal experiments and in vitro testing.

High-performance liquid chromatography (HPLC) analysis. The Agilent 1260 HPLC system (Agilent Technologies, Inc. Santa Clara, CA, USA), consisting of a quaternary pump, autosampler, column oven and diode array detector, was utilized to analyze the samples. Chromatographic separation was performed using a SepaxGP-C18 column $(5.0 \mu \mathrm{m}$, 4.6x250 mm; Sepax Technologies, Inc., Newark, DE, USA) at $40^{\circ} \mathrm{C}$. The flow rate was $1.0 \mathrm{ml} / \mathrm{min}$ and the injection volume was $20 \mu 1$. The mobile phase was a mixture of phosphoric acid solution ( $\mathrm{pH} 3.0$; $\mathrm{A}$ ) and acetonitrile (B; $\mathrm{A}: \mathrm{B}=8: 92)$. The chromat $\mu$ ograms were recorded at $220 \mathrm{~nm}$. For quantitative analysis, the Fag extract and the standard solution mixtures of protocatechuic acid, catechin, epicatechin, procyanidins $B_{1}$ and procyanidins $B_{2}$ were analyzed under the conditions described above $\left(40^{\circ} \mathrm{C}\right)$. Compounds were run at six different concentrations (protocatechuic acid, 13.47-215.52 $\mu \mathrm{g} / \mathrm{ml}$; catechin, $10.21-163.36 \mu \mathrm{g} / \mathrm{ml}$; epicatechin, $12.35-197.60 \mu \mathrm{g} / \mathrm{ml}$; procyanidins $\mathrm{B}_{1}, 6.16-98.56 \mu \mathrm{g} / \mathrm{ml}$; and procyanidins $\mathrm{B}_{2}, 5.99$ to $95.84 \mu \mathrm{g} / \mathrm{ml}$ ) with a $20 \mu \mathrm{l}$ injection volume. Compound content in the extract was assessed using linear regression analysis and was demonstrated to be linear in the range with a correlation coefficient of 0.997-0.999.

Animal experiments. A total of 58 male BALB/c mice (8 weeks old, 18-22 g) were obtained from Nantong University (Nantong, China; certificate no. SCXK-2008-0010). The mice were housed in an air-conditioned room at $20-22^{\circ} \mathrm{C}$ and $80 \%$ humidity with a 12-h light/dark cycle and were provided with ad libitum access to standard laboratory chow and water. Animal experiments were conducted in accordance with protocols approved by the Animal Ethic Committee of the Nanjing University of Chinese Medicine. Mice were randomly divided into the following six groups: Control group $(n=8)$, TNBS-induced colitis groups treated with different concentrations of Fag ( $\mathrm{n}=10$ per group; 0, 0.57, 1.14 and $2.28 \mathrm{~g} / \mathrm{kg}$ ) and the $200 \mathrm{mg} / \mathrm{kg}$ SASP group $(\mathrm{n}=10)$. Acute colitis was induced in BALB/c mice as previously described with modifications (27). Briefly, mice were fasted for $24 \mathrm{~h}$ and anesthetized with pentobarbital (50 mg/kg; Sigma-Aldrich; Merck KGaA). TNBS solution $(2.5 \% \mathrm{w} / \mathrm{v} ; 100 \mu \mathrm{l})$ in $50 \%$ ethanol was administered into the colon via a thin catheter $4 \mathrm{~cm}$ proximal to the anus. The control group received vehicle (50\% ethanol) alone. Fag and SASP were orally administrated once a day for 3 days following TNBS treatment. Mice were sacrificed $24 \mathrm{~h}$ following the final administration of test agents.

Macroscopic scoring and histological analysis of colitis. Mice were inspected and weighed daily. Following the induction of colitis, animals were sacrificed and colons were harvested and gently washed with ice-cold PBS. Colonic tissue was then stored at $-80^{\circ} \mathrm{C}$ for further experiments.

For histological analysis, colon tissues were fixed in $4 \%$ paraformaldehyde at room temperature for $24 \mathrm{~h}$, dehydrated in a graded series of ethanol, embedded in paraffin and finally cut into $4-\mu \mathrm{m}$ thick sections. The samples were stained with hematoxylin and eosin (room temperature, hematoxylin for $5 \mathrm{~min}$ and eosin for $2 \mathrm{~min}$ ) in accordance with the standard procedures for histological evaluation (28). Histological scores were calculated by a blinded investigator on a scale from 0-9 based on the following criteria for inflammation: i) Erythema, ii) hemorrhage, iii) edema, iv) stricture formation, v) ulceration, vi) fecal blood, vii) presence of mucus, viii) diarrhea and ix) adhesions, with 1 point awarded for each parameter observed using a light microscope at magnification, x20. A maximum score of 9 indicated severe colitis with an overall diffuse pattern of chronic changes.

Colonic myeloperoxidase (MPO) activity. MPO activity is an indicator of neutrophil infiltration into the inflamed colon $(n=6)(26,27)$. MPO activity was assessed using an MPO activity kit (cat. no. A044; Nanjing Jiancheng Bioengineering Institute, Nanjing, China). Briefly, colons were homogenized 
in $10 \mathrm{mM}$ PBS containing $0.5 \%$ hexadecyltrimethylammonium bromide ( $\mathrm{pH} 7.0)$, and centrifuged at $4^{\circ} \mathrm{C}$ and $12,000 \mathrm{x} \mathrm{g}$ for $10 \mathrm{~min}$. The supernatant $(50 \mu \mathrm{l})$ was added to a reaction mixture containing $0.1 \mathrm{mM} \mathrm{H}_{2} \mathrm{O}_{2}$ and $1.6 \mathrm{mM}$ tetramethylbenzidine and incubated at $37^{\circ} \mathrm{C}$. Absorbance was measured at $650 \mathrm{~nm}$. Myeloperoxidase activity was defined as the quantity degrading $1 \mu \mathrm{mol} / \mathrm{ml}$ of peroxide at $37^{\circ} \mathrm{C}$ and expressed as $\mathrm{U} / \mathrm{mg}$.

Immunohistochemical evaluation. F4/80 positive inflammatory cell infiltration analysis was performed on paraffin-embedded colon tissue sections. The sections were deparaffinized, rehydrated with xylene and graded ethanol solutions, and washed with PBS. After blocking with 5\% bovine serum albumin (Sigma-Aldrich; Merck KGaA) for $1 \mathrm{~h}$ at $37^{\circ} \mathrm{C}$, the sections were incubated with primary antibodies against F4/80 (cat. no. 14-4801-81; eBioscience; Thermo Fisher Scientific, Inc., Waltham, MA, USA) at a dilution of $1: 50$ for $2 \mathrm{~h}$ at $37^{\circ} \mathrm{C}$, washed with PBS and subsequently co-incubated with biotinylated secondary antibody (cat. no. KS010; Nanjing Jiancheng Bioengineering Institute) for $30 \mathrm{~min}$ at room temperature at a dilution of 1:2,000. Following washing with PBS ( $\mathrm{pH} 7.4$ ), tissue sections were incubated at $37^{\circ} \mathrm{C}$ with a horseradish peroxidase (HRP)-streptavidin complex (cat. no. KS001; Nanjing Jiancheng Bioengineering Institute) to detect secondary antibody for $30 \mathrm{~min}$. Sections were stained with DAB at room temperature for $5 \mathrm{~min}$ and mounted according to standard protocols and observed under a light microscope at magnification, $\mathrm{x} 20$.

Determination of cytokine and LPS in plasma. The mouse plasma concentrations ( $\mathrm{n}=6)$ of IL-1 $\beta$ (cat. no. 432601), IL-6 (cat. no. 431304), and TNF- $\alpha$ (cat. no. 430904) were determined using commercially available ELISA kits (BioLegend, Inc., San Diego, CA, USA), and the lower limit of quantification was $7.8 \mathrm{pg} / \mathrm{ml}$ for each cytokine. LPS $(\mathrm{n}=6)$ was measured using a Limulus Amebocyte Lysate assay kit (Xiamen Bioendo Technology, Co., Ltd., Xiamen, China) according to the manufacturer's protocol.

Reverse transcription-quantitative polymerase chain reaction $(R T-q P C R)$. Total RNA was extracted from colonic tissue $(n=5)$ using TRIzol (Thermo Fisher Scientific, Inc.). A Takara PrimeScript First Strand cDNA Synthesis kit (Takara Bio, Inc., Otsu, Japan) was employed for the RT reactions with a temperature protocol as follows: $37^{\circ} \mathrm{C}$ for $15 \mathrm{~min}, 85^{\circ} \mathrm{C}$ for $15 \mathrm{sec}$ and $4^{\circ} \mathrm{C}$ for $10 \mathrm{~min}$. qPCR analysis was performed in an ABI StepOnePlus Real-Time PCR system (Applied Biosystems; Thermo Fisher Scientific, Inc.) with a temperature protocol as follows: $95^{\circ} \mathrm{C}$ for $3 \mathrm{~min} ; 95^{\circ} \mathrm{C}$ for $30 \mathrm{sec}, 58^{\circ} \mathrm{C}$ for $30 \mathrm{sec}$ and $72^{\circ} \mathrm{C}$ for $30 \mathrm{sec}(35 \mathrm{cycles})$. The sequences of primers used in this experiment were as follows: IL- $1 \beta$ forward, 5'-CTGTGTCTTTCCCGTGGACC-3' and reverse, 5'-CAGCTCATATGGGTCCGACA-3'; IL-6 forward, 5'-CCA GAAACCGCTATGAAGTTCCT-3' and reverse, 5'-CACCAG CATCAGTCCCAAGA-3'; TNF- $\alpha$ forward, 5'-ATCCGCGAC GTGGAACTG-3' and reverse, 5'-CAGCTCATATGGGTC CGACA-3'; and $\beta$-actin forward, 5'-TCTGGCACCACACCT TCTA-3' and reverse, 5'-AGGCATACAGGGACAGCAC-3'. The SYBR-Green PCR mix kit (Takara Bio, Inc.) was used to quantify gene expression. Reactions were performed in a total volume of $20 \mu \mathrm{l}$ following the manufacturer's protocol. Three replicates were performed for each qPCR run. The mRNA concentrations of all target genes were normalized to that of the $\beta$-actin in each sample using the $2^{-\Delta \Delta C \mathrm{Cq}}$ method (29).

Cell culture and treatment. Raw264.7 cells (Nanjing KeyGen Biotech Co., Ltd., Nanjing, China) were treated with 0, 5, 10, 20 or $50 \mu \mathrm{g} / \mathrm{ml} \mathrm{Fag}$ for $30 \mathrm{~min}$ followed by incubation with $0.5 \mu \mathrm{g} / \mathrm{ml}$ LPS for $24 \mathrm{~h}$. Cells with no treatment were set as the control group, and the cells only treated with LPS were set as model group. Dexamethasone (Dex; $1 \mu \mathrm{M}$ ) was selected as the positive drug and the treatment time was the same as the Fag treatment. The inhibitory effects of Fag on TNF- $\alpha$ and IL-6 production were measured using the aforementioned ELISA kits in supernatants collected from cells of 3 independent experiments run in triplicate.

Western blotting. Raw264.7 cells were pretreated with 0, 10 , 20 , or $50 \mu \mathrm{g} / \mathrm{ml} \mathrm{Fag} \mathrm{for} 30 \mathrm{~min}$. LPS was added to a final concentration of $0.5 / \mathrm{ml}$ and incubated at $37^{\circ} \mathrm{C}$ for $4 \mathrm{~h}$. Cells were harvested and nuclear and cytoplasmic extracts were prepared using Nuclear and Cytoplasmic Extraction Reagents (Beyotime Institute of Biotechnology, Haimen, China) with protease inhibitor cocktail (Sangon Biotech Co., Ltd., Shanghai, China). All protein samples were quantified using a BCA assay kit (Beyotime Institute of Biotechnology). The protein samples $(50 \mu \mathrm{g})$ were separated by $10 \%$ SDS-PAGE and transferred onto a polyvinylidene difluoride membrane (Bio-Rad Laboratories, Inc., Hercules, CA, USA). The membrane was blocked with $5 \%$ bovine serum albumin for $1 \mathrm{~h}$ at $37^{\circ} \mathrm{C}$, followed by incubation with antibodies against

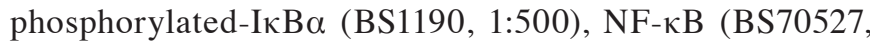
1:500), cyclooxygenase 2 (Cox-2) (BS1076, 1:500), inducible nitric oxide synthase (iNOS) (BS1267, 1:1,000), $\beta$-actin (AP0060, 1:2,000) or Lamin A (BS1446, 1:2,000) (all from Bioworld Technology, Inc., St. Louis Park, MN, USA) at $4^{\circ} \mathrm{C}$ overnight. Membranes were subsequently incubated at $37^{\circ} \mathrm{C}$ for $1 \mathrm{~h}$ with an HRP-conjugated secondary antibody (BS13278, 1:10,000; Bioworld Technology, Inc.). Antibody signals were detected using an enhanced chemiluminescence kit (Thermo Fisher Scientific, Inc.) and images were captured using a ChemiDoc XRS+ system (Bio-Rad Laboratories, Inc.).

Data analysis. Data are expressed as the mean \pm standard deviation. Statistical analysis was performed using a two-tailed Student's t-test and one-way analysis of variance (with Tukey's post hoc test). $\mathrm{P}<0.05$ was considered to indicate a statistically significant difference.

Clinical analysis. A total of 60 patients were recruited from Haian Hospital of Traidtional Chinese Medicine (Haian, China) from May 2013 to July 2015 [37.8 7.8 years old; $32(53.3 \%)$ male; $28(46.7 \%)$ female; $48(80.0 \%)$ with stomachache; 58 (96.7\%) with diarrhea; 46 (76.6\%) with mucous bloody stool] were randomly divided into the experimental and control groups ( $\mathrm{n}=30$ in each). Patients in the experimental group were administered with 5 jinqiaomaipian tablets $(0.33 \mathrm{~g}$ Fag/tablet; Nantong Jinghua Pharmaceutical Co., Ltd., Nantong, China) 
3 times daily for 2 months. Patients in the control group were administered with $1 \mathrm{~g}$ SASP 4 times per day for the first month and twice daily for the second month. Glucocorticoid and 5-aminosalicylic acid analogues were avoided throughout the study period. The clinical study was approved by the Ethics Committee of Haian Hospital of Traditional Chinese Medicine, and all patients provided informed consent.

According to the Chinese Consensus on Diagnosis and Treatment Standard of Inflammatory Bowel Disease (2007), curative effects were grouped into three levels: Complete remission, effective and invalid. The total efficiency was calculated by the following formula: Total efficiency $(\%)=($ total number of complete remissions/total number of cases) x 100 .

\section{Results}

Effective components in Fag extracts. Fag extracts were analyzed using an established sensitive HPLC method within $70 \mathrm{~min}$ and the components were well separated (Fig. 1). The effective compounds, including protocatechuic acid, procyanidin $B_{1}$, catechin, procyanidin $B_{2}$ and epicatechin, had retention times of 9.46, 25.84, 32.19, 44.87 and $53.17 \mathrm{~min}$, respectively (Fig. 1). Furthermore, quantification was also performed using HPLC. The results revealed that there was $6.98 \mathrm{mg}$ protocatechuic acid, $4.07 \mathrm{mg}$ procyanidin $\mathrm{B}_{1}, 2.64 \mathrm{mg}$ catechin, $8.43 \mathrm{mg}$ procyanidin $\mathrm{B}_{2}$ and $17.84 \mathrm{mg}$ epicatechin per $g$ of the crude $50 \%$ ethanol extracts.

Fag ameliorates the symptoms of TNBS-induced colitis in mice. It has previously been demonstrated that TNBS induces colitis in mice (30). Following treatment with TNBS in 50\% ethanol, the mice were inappetent, exhausted and emaciated, and had diarrhea with bloody and purulent stool, indicating that severe inflammation in the colon, or colitis. Weight loss and shortening of the colon were detected in the TNBS-treated mice (Fig. 2). Treatment with SASP ameliorated TNBS-induced weight loss and colon shortening when comparing with the TNBS treated mice $(\mathrm{P}<0.01)$. Fag was demonstrated to significantly ameliorate weight loss and colon shortening compared with the TNBS group in a dose-dependent manner $(0.57 \mathrm{~g} / \mathrm{kg}$, $\mathrm{P}<0.05 ; 1.14$ and $2.28 \mathrm{~g} / \mathrm{kg}, \mathrm{P}<0.01$; Fig. 2). Although it was not as effective as SASP, treatment with Fag extracts improved colon health in mice with TNBS-induced colitis.

Histopathology. Histopathological analysis was utilized to evaluate the severity of colonic inflammation and ulceration. There was clear evidence of mucosal damage in the TNBS-treated mice, characterized by crypt abscesses, neutrophils, mononuclear infiltrating glandular epithelium and epithelial hyperplasia (Fig. 3A). Following treatment with Fag extract or SASP, mouse colons exhibited intact colonic architecture with no apparent ulceration, indicating less inflammatory cell infiltration compared with the TNBS group (Fig. 3A). Histopathological scoring was used to quantify the colon damage, and a marked increase was observed in the TNBS group compared with the control group $(\mathrm{P}<0.01$; Fig. 3B). Treatment with Fag extract induced a dose-dependent decrease in histopathological scores $(\mathrm{P}<0.05$ for the $0.57 \mathrm{~g} / \mathrm{kg}$ group and $\mathrm{P}<0.01$ for the 1.14 and $2.28 \mathrm{~g} / \mathrm{kg}$ groups), which was also observed in the SASP group ( $\mathrm{P}<0.01$; Fig. 3B).

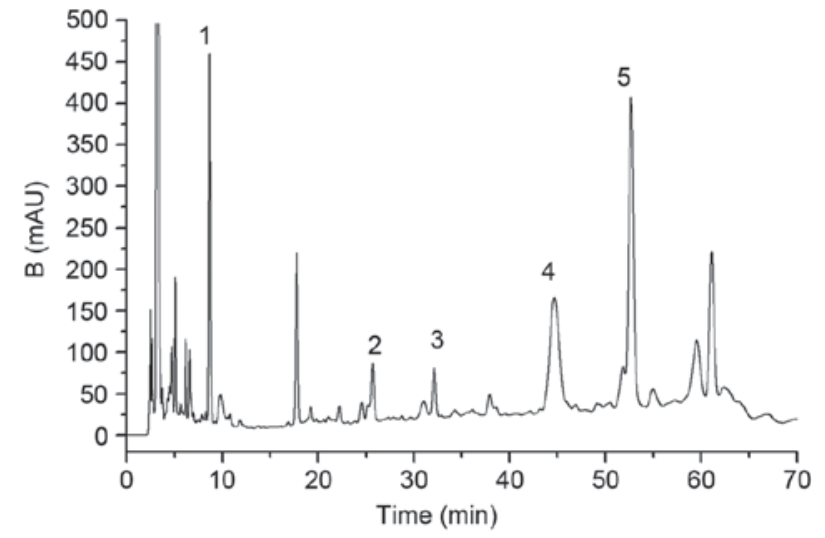

Figure 1. High performance liquid chromatography chromatogram of $50 \%$ ethanol extract solution of Fagopyrum cymosum (Trev.) Meisn. B, intensity; $\mathrm{t}$, retention time; 1 , protocatechuic acid; 2 , procyanidin $\mathrm{B}_{1} ; 3$, catechin; 4 , procyanidin $\mathrm{B}_{2} ; 5$, epicatechin.

Immunohistochemistry. To further evaluate the protective effects of Fag on TNBS-induced colitis, immunohistochemical analysis of F4/80 was employed. An increased number of F4/80 positive inflammatory cells was observed in TNBS-treated mice mucosa compared with the control group, whereas treatment with Fag or SASP were observed to inhibit this increase (Fig. 4A). MPO activity was also evaluated, and was demonstrated to be significantly increased in the TNBS group compared with the control group (14.4 fold; $\mathrm{P}<0.01$; Fig. 4B). The MPO activity increase was significantly ameliorated following SASP treatment or treatment with 1.14 or $2.28 \mathrm{~g} / \mathrm{kg}$ Fag $(\mathrm{P}<0.01$; Fig. 4B).

Fag decreases proinflammatory cytokine and LPS levels. The levels of IL-1 $\beta$, IL- 6 and TNF- $\alpha$ mRNA were significantly increased in the TNBS group compared with the control group $(\mathrm{P}<0.01$; Fig. 5). Following treatment with SASP, the mRNA expressions of IL-1 $\beta$, IL- 6 and TNF- $\alpha$ were significantly decreased compared with the TNBS-treated group (all $\mathrm{P}<0.01$; Fig. 5). Fag also significantly attenuated the expression of IL-1 $\beta$, IL-6 and TNF- $\alpha$ compared with the TNBS group in a dose-dependent manner ( $\mathrm{P}<0.05$; Fig. 5).

LPS is the major component of the outer membrane of Gram-negative bacteria, and it has been reported that LPS is upregulated in patients with IBD due to gut leakage and microbiota dysbiosis (31). Following treatment with TNBS for 3 days, the level of LPS in peripheral plasma was significantly increased in the TNBS group compared with the control group $(\mathrm{P}<0.01$; Fig. 6A). Treatment with Fag significantly decreased the LPS level in a dose-dependent manner $(1.14 \mathrm{~g} / \mathrm{kg}, \mathrm{P}<0.05$; $2.28 \mathrm{~g} / \mathrm{kg}, \mathrm{P}<0.01$; Fig. 6A). Furthermore, SASP treatment significantly ameliorated the TNBS-induced increase in LPS $(\mathrm{P}<0.01$; Fig. 6A). Plasma levels of IL-1 $\beta$, IL-6, and TNF- $\alpha$ were significantly increased in the TNBS group compared with the control $(\mathrm{P}<0.01$; Fig. 6B-D), and these increases were significantly ameliorated by treatment with SASP $(\mathrm{P}<0.01)$ or Fag in a dose-dependent manner $(1.14 \mathrm{~g} / \mathrm{kg}, \mathrm{P}<0.05 ; 2.28 \mathrm{~g} / \mathrm{kg}$, $\mathrm{P}<0.01$; Fig. 6B-D).

Fag reduces proinflammatory cytokines in LPS-stimulated macrophages. LPS levels may be used as a marker of 
A

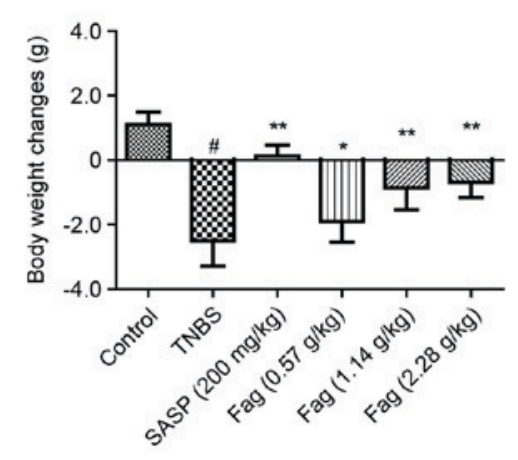

B

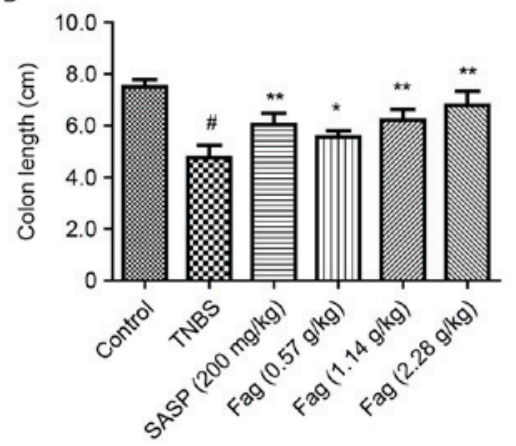

C

Control

TNBS

SASP $200 \mathrm{mg} / \mathrm{kg}$

Fag $0.57 \mathrm{~g} / \mathrm{kg}$

Fag $1.14 \mathrm{~g} / \mathrm{kg}$

Fag $2.28 \mathrm{~g} / \mathrm{kg}$

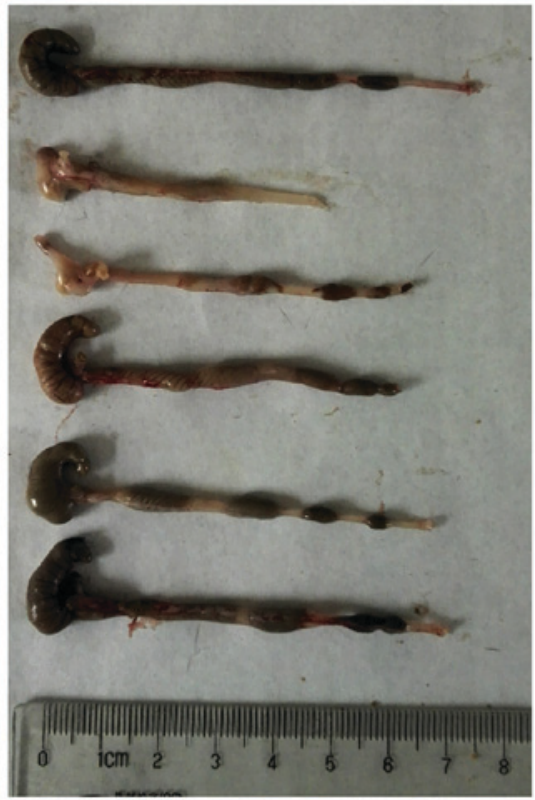

Figure 2. Fag ameliorates colitis induced by TNBS in mice. (A) Body weight change, (B) colonic length and (C) colonic appearance in mice following treatment. $\mathrm{n}=8$ for control mice and $\mathrm{n}=10$ for other treatment groups. ${ }^{*} \mathrm{P}<0.01$ vs. control group; ${ }^{*} \mathrm{P}<0.05$ and ${ }^{* *} \mathrm{P}<0.01$, vs. TNBS group. Fag, Fagopyrum cymosum (Trev.) Meisn; TNBS, 2,4,6-trinitrobenzenesulfonic acid; SASP, salicylazosulfapyridine.

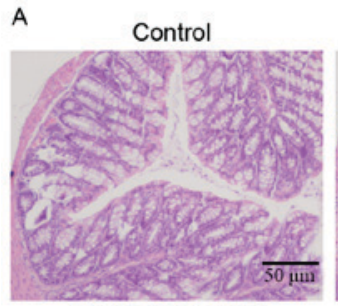

SASP $200 \mathrm{mg} / \mathrm{kg}$

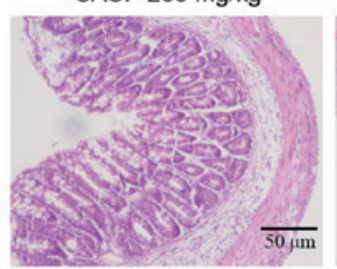

Fag $1.14 \mathrm{~g} / \mathrm{kg}$

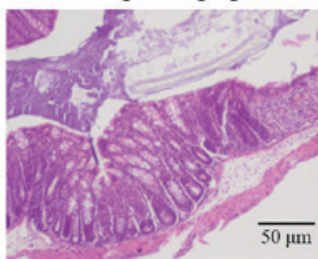

TNBS

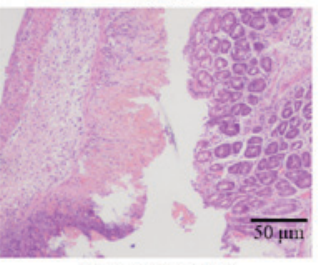

Fag $0.57 \mathrm{~g} / \mathrm{kg}$

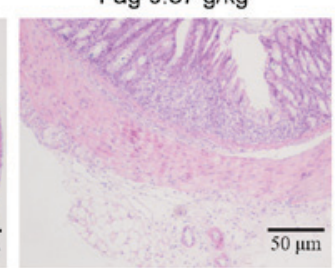

Fag $2.28 \mathrm{~g} / \mathrm{kg}$

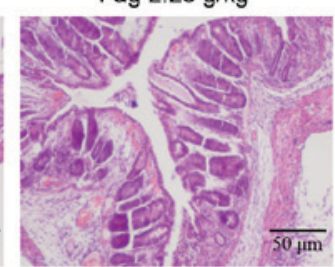

B

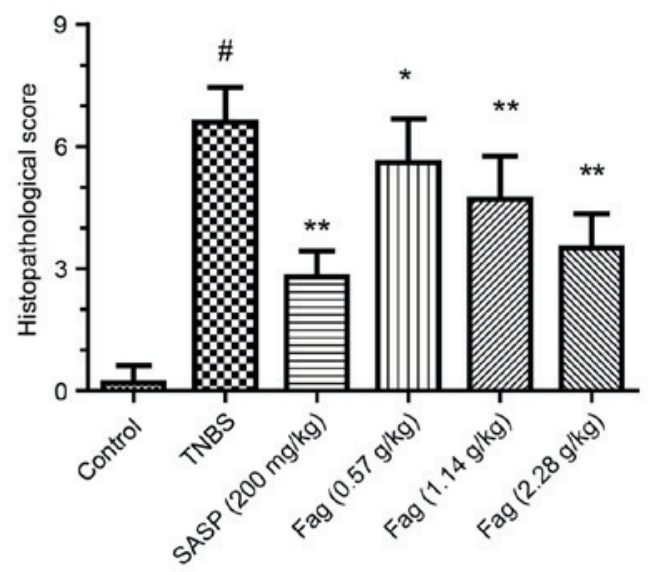

Figure 3. Fag treatment protects against TNBS-induced colon damage in mice. (A) Representative colonic tissue stained with hematoxylin and eosin. (B) Histopathological score of the colon. $\mathrm{n}=8$ for control mice and $\mathrm{n}=10$ for other treatment groups. ${ }^{*} \mathrm{P}<0.01$ vs. control group; ${ }^{*} \mathrm{P}<0.05$ and ${ }^{* *} \mathrm{P}<0.01$, vs. TNBS group. Fag, Fagopyrum cymosum (Trev.) Meisn; TNBS, 2,4,6-trinitrobenzenesulfonic acid; SASP, salicylazosulfapyridine.

inflammation in vivo, and LPS stimulates the inflammatory response of macrophages in vitro (31). Raw264.7 cells were used to verify the in vitro anti-inflammatory effects of Fag. LPS stimulation significantly increased the production of TNF- $\alpha$ and IL-6 in RAW264.7 cells $(\mathrm{P}<0.01)$, and Fag treatment significantly ameliorated these LPS-induced increases $(\mathrm{P}<0.01$; Fig. 7) in a dose-dependent manner. iNOS and Cox-2 are two injury-induced enzymes in macrophages. Western blotting results demonstrated that LPS-induced overexpression of iNOS and Cox-2 was ameliorated by Fag treatment in vitro (Fig. 8).v 


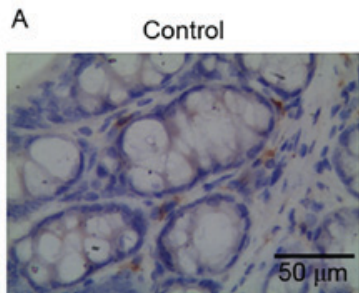

Fag $0.57 \mathrm{~g} / \mathrm{kg}$

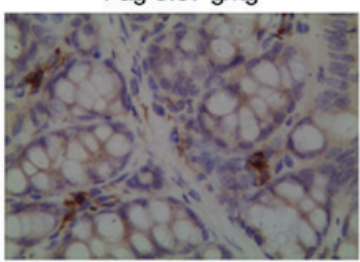

TNBS

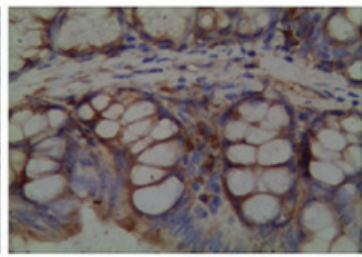

Fag $1.14 \mathrm{~g} / \mathrm{kg}$

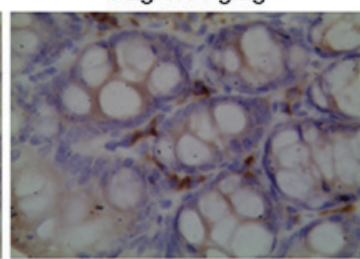

SASP $200 \mathrm{mg} / \mathrm{kg}$

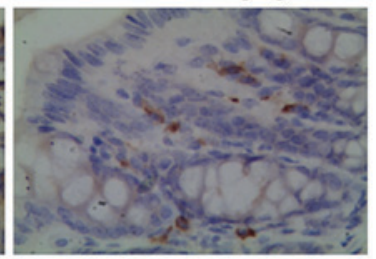

Fag $2.28 \mathrm{~g} / \mathrm{kg}$

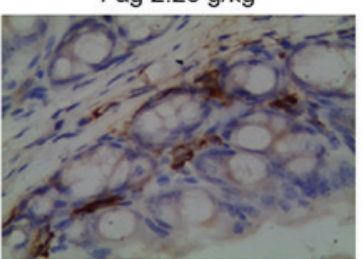

B

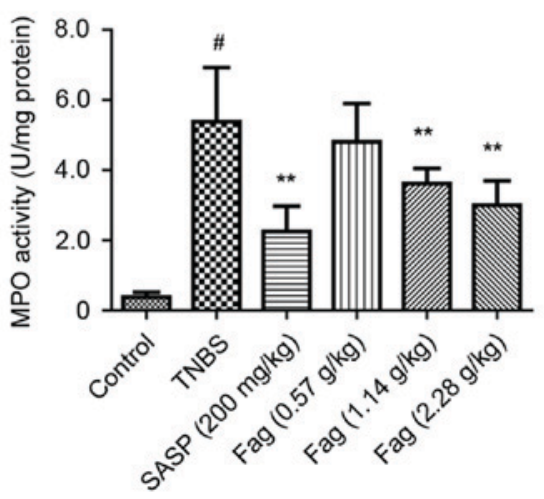

Figure 4. Fag attenuates inflammatory cell infiltration in TNBS-induced colitis mice. (A) Immunohistochemical analysis of F4/80-positive inflammatory cells. (B) Colonic myeloperoxidase activity in each group. $\mathrm{n}=6 .{ }^{*} \mathrm{P}<0.01$ vs. control group and ${ }^{* *} \mathrm{P}<0.01$, vs. TNBS group. Fag, Fagopyrum cymosum (Trev.) Meisn; TNBS, 2,4,6-trinitrobenzenesulfonic acid; SASP, salicylazosulfapyridine.

A

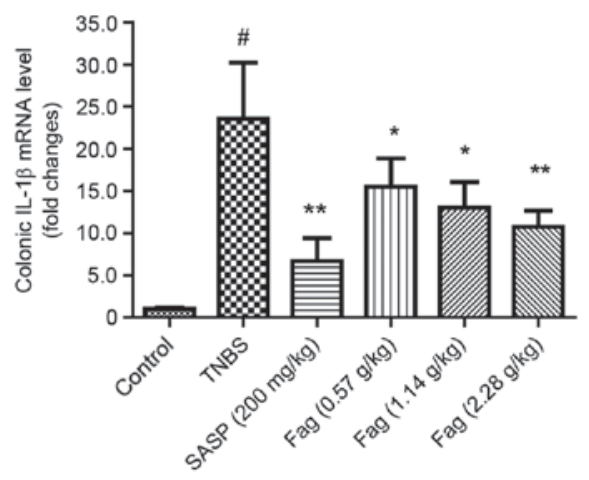

B

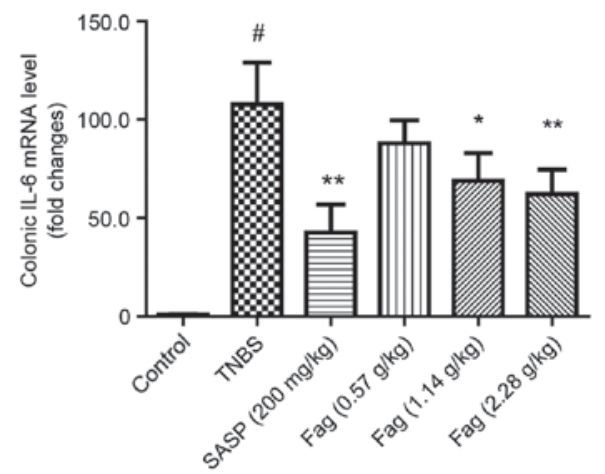

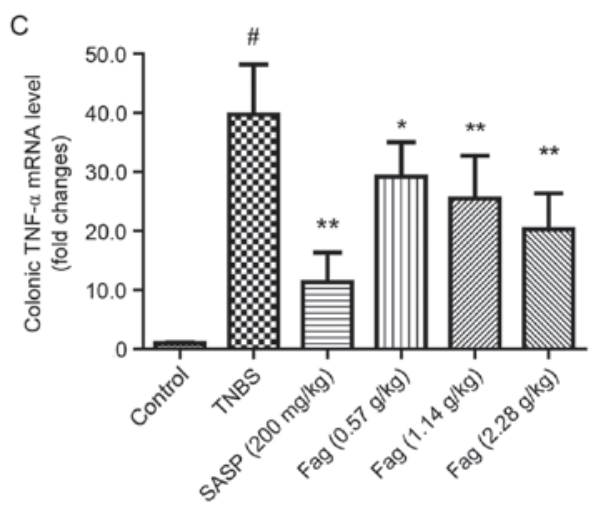

Figure 5. Fag reduces (A) IL-1 $\beta$, (B) IL-6 and (C) TNF- $\alpha$ mRNA expression in the colon of TNBS-induced colitis mice. $n=5$. ${ }^{\#} \mathrm{P}<0.01$ vs. control group; ${ }^{*} \mathrm{P}<0.05$ and ${ }^{* *} \mathrm{P}<0.01$, vs. TNBS group. Fag, Fagopyrum cymosum (Trev.) Meisn; IL, interleukin; TNF, tumor necrosis factor; TNBS, 2,4,6-trinitrobenzenesulfonic acid; SASP, salicylazosulfapyridine. 

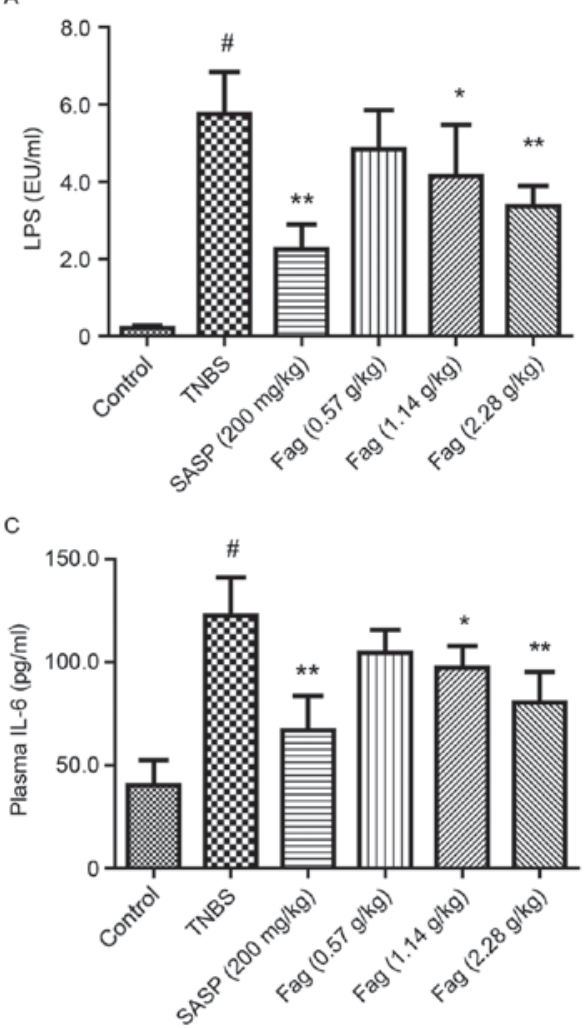
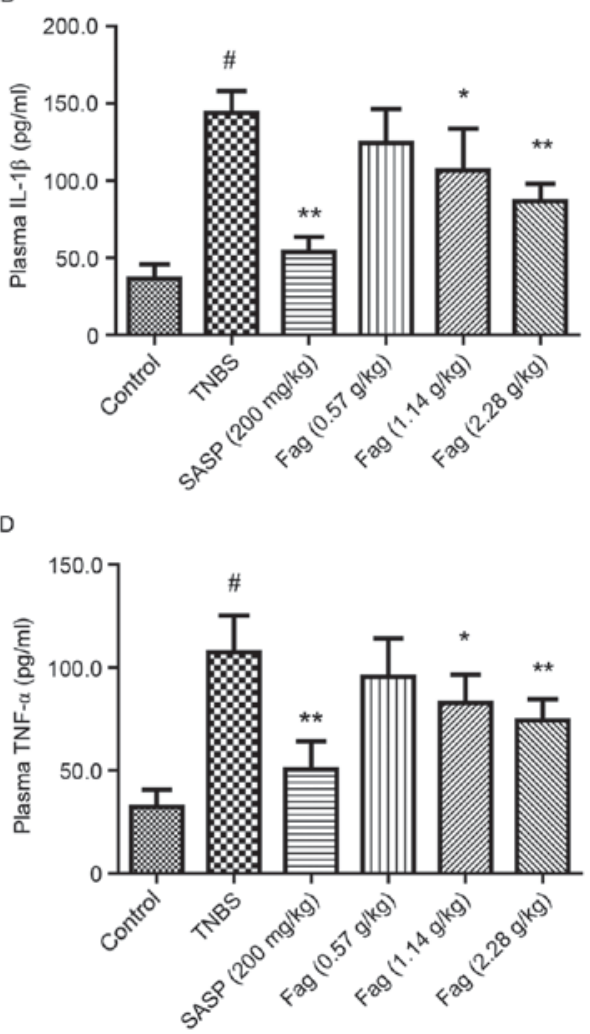

Figure 6. Fag decreases the plasma levels of (A) LPS, (B) IL-1 $\beta$, (C) IL-6 and (D) TNF- $\alpha$ in TNBS-induced colitis mice. $n=6$. " $\mathrm{P}<0.01$ vs. control group; ${ }^{*} \mathrm{P}<0.05$ and ${ }^{* *} \mathrm{P}<0.01$, vs. TNBS group. Fag, Fagopyrum cymosum (Trev.) Meisn; LPS, lipopolysaccharide; IL, interleukin; TNF, tumor necrosis factor; TNBS, 2,4,6-trinitrobenzenesulfonic acid; SASP, salicylazosulfapyridine.

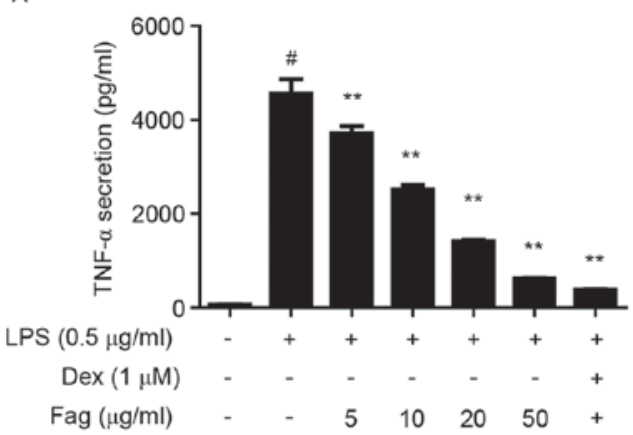

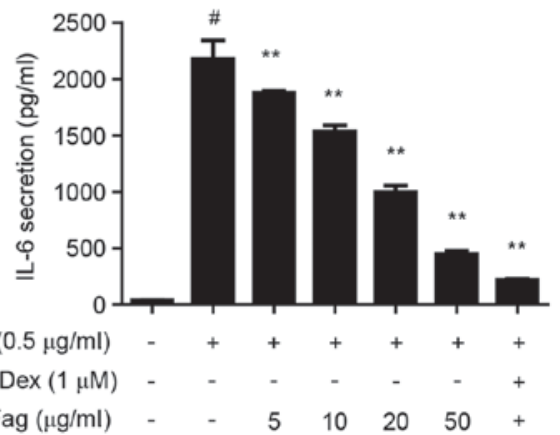

Figure 7. Fag inhibits the production of (A) TNF- $\alpha$ and (B) IL-6 in LPS-stimulated RAW264.7 cells. $n=3 .{ }^{*} \mathrm{P}<0.01$ vs. untreated RAW264.7 cells; ${ }^{* *} \mathrm{P}<0.01$ vs. LPS-stimulated RAW264.7 cells. Fag, Fagopyrum cymosum (Trev.) Meisn; TNF, tumor necrosis factor; IL, interleukin; LPS, lipopolysaccharide; Dex, dexamethasone.

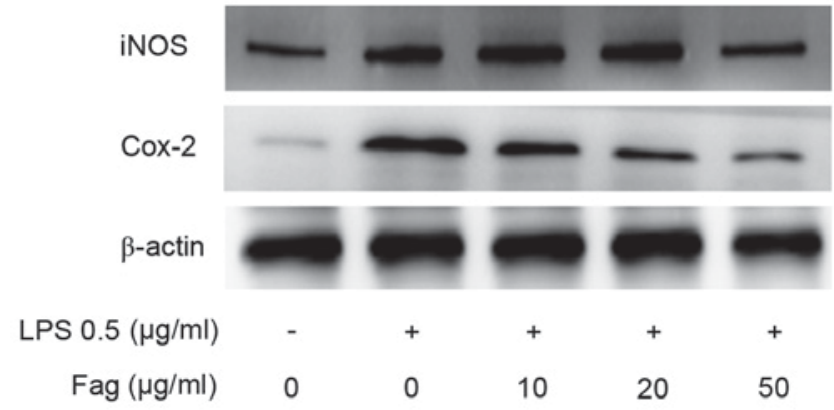

Figure 8. Fag inhibits the production of iNOS and Cox-2 in LPS-stimulated RAW264.7 cells. Fag, Fagopyrum cymosum (Trev.) Meisn; iNOS, inducible nitric oxide; Cox-2, cyclooxygenase-2; LPS, lipopolysaccharide.
Western blotting was used to investigate the effect of Fag on NF-kB activation signaling. The results revealed that Fag attenuated the LPS-induced nuclear translocation of $\mathrm{p} 65$ NF- $\mathrm{BB}$ in a dose-dependent manner (Fig. 9). Although the exact mechanism by which this occurs is not fully understood, the western blotting results indicate that Fag was able to inhibit I $\mathrm{B} \alpha$ phosphorylation in LPS-induced cells in vitro (Fig. 9).

Fag efficiently treatsv IBD with fewer side effects than SASP. The results of the clinical study demonstrate that jinqiaomaipian was able to ameliorate stomachache, diarrhea and mucous bloody stool with a total efficiency of $\sim 80 \%$ (Table I). 
Table I. Clinical study of jinqiaomaipian treatment for ulcerative colitis.

\begin{tabular}{|c|c|c|c|c|c|c|}
\hline Group & $\begin{array}{c}\text { Clinical } \\
\text { manifestation }\end{array}$ & $\begin{array}{c}\text { Total } \\
\text { cases (n) }\end{array}$ & $\begin{array}{l}\text { Complete } \\
\text { remission (n) }\end{array}$ & Effective (n) & $\begin{array}{l}\text { Invalid } \\
\text { (n) }\end{array}$ & $\begin{array}{c}\text { Total } \\
\text { efficiency (\%) }\end{array}$ \\
\hline \multirow[t]{4}{*}{ Experimental group } & Stomachache & 23 & 13 & 6 & 4 & 82.6 \\
\hline & Diarrhea & 28 & 12 & 10 & 6 & 78.6 \\
\hline & Mucous bloody stool & 24 & 11 & 8 & 5 & 79.2 \\
\hline & Colonoscopy & 30 & 12 & 13 & 5 & 83.3 \\
\hline \multirow[t]{4}{*}{ Control group } & Stomachache & 25 & 11 & 10 & 4 & 84.0 \\
\hline & Diarrhea & 30 & 9 & 13 & 8 & 73.3 \\
\hline & Mucous bloody stool & 22 & 10 & 8 & 4 & 81.8 \\
\hline & Colonoscopy & 30 & 12 & 11 & 7 & 76.7 \\
\hline
\end{tabular}

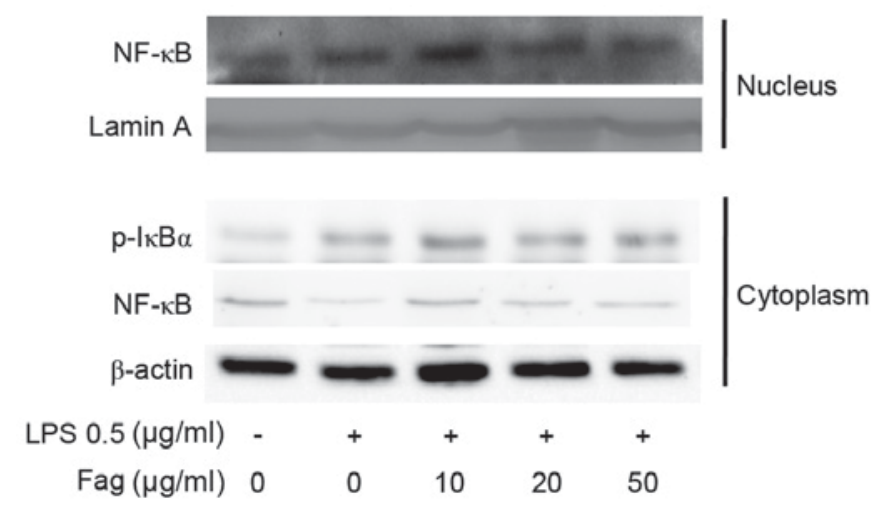

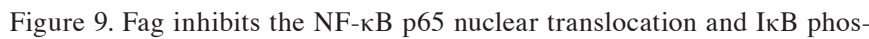
phorylation in Raw264.7 cells. Fag, Fagopyrum cymosum (Trev.) Meisn;

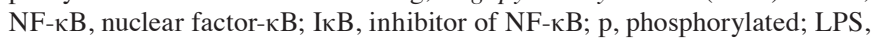
lipopolysaccharide.

No significant difference was observed between the control and experimental groups, suggesting that Fag may be as effective as SASP for the treatment of IBD.

Of the 30 patients in the SASP group, 9 (30.0\%) experienced side effects (3 nausea, 3 abdominal discomfort, 1 headache, and 2 leukopenia). However, only 1 out of 30 patients $(3.3 \%)$ in the experimental group experienced nausea. The incidence of side effects was significantly lower in the experimental group $(\mathrm{P}<0.01$; data not shown).

\section{Discussion}

Recent studies have demonstrated that IBD cannot be cured using medication, and treatment mainly focuses on increasing remission periods and improving patient quality of life $(17,32)$. Novel pharmacological agents and natural medicines for treating IBD are urgently needed. TNBS-induced colitis in mice is a well-established animal model with an enhanced Th1/Th17 response (27). As the process is similar to the cluster of differentiation-related immune response (28), the TNBS-induced murine model has been widely used for screening IBD treatments and exploring the therapeutic effects of potential agents.

Fag is a traditional Chinese medicine used to treat bacterial dysentery, lung infection and rheumatism $(22,24,26)$. It has previously been demonstrated that there are effective treatment components in the ethanol extract of Fag, including luteolin (22) and epicatechin (24). Fag has been reported to exert anti-inflammatory effects in Raw264.7 cells via inhibiting p38 and c-Jun N-terminal kinase phosphorylation (33) or inducing $67 \mathrm{kD}$ alaminin receptor internalization (34). To the best of our knowledge, the present study is the first time that the anti-inflammatory effects of Fag extract on TNBS-induced colitis have been reported.

In the present study, the TNBS-induced mouse model was used to evaluate the protective effects of ethanol extract of Fag on colitis. The anti-inflammatory effects of Fag in LPS-induced RAW264.7 macrophages were also verified. The results demonstrated that oral administration of ethanol extract of Fag ameliorated TNBS-induced colitis in mice, reducing body weight loss and colon shortening. The staining results confirmed that Fag effectively decreased mucosal erosion, submucosal edema and disruption of crypts and villi, which are crucial for maintaining normal colonic function $(25,35)$. These mucosal events significantly affect the structure and function of tight junctions, leading to a damaged intestinal barrier and immune activation (36). Subsequently, proinflammatory cytokines are overexpressed, triggering the signaling cascade of inflammation and leading to inflammatory cell infiltration in the inflamed mucosa (37). The results of the present study revealed that ethanol extract of Fag effectively reduced macrophage infiltration in the colon of TNBS-induced mice, with F4/80 and colonic MPO activity used as macrophage markers (35).

On the molecular level, the colonic levels of proinflammatory cytokines, including IL-1 $\beta$, IL- 6 and TNF- $\alpha$, correlate with the degree of inflammation (35). These cytokines serve an important role in the pathogenesis of various inflammatory diseases $(38,39)$. Colonic levels of IL-1 $\beta$, IL-6 and TNF- $\alpha$ mRNA in TNBS-induced colitis mice were markedly reduced following treatment with Fag. Previous studies have also reported that IL- 6 and TNF- $\alpha$ are able to significantly decrease barrier function by influencing tight junction proteins, including claudin, occludin, and zonula occludens-1 $(40,41)$. The inflamed colon may result in gut leakage and bacterial translocation (37). In the present study, an increased plasma LPS level was identified in TNBS-induced colitis mice, suggesting that bacteria were translocated to the circulation via the leaky gut (42). The administration of Fag significantly 
decreased the plasma LPS level in TNBS-treated mice, as well as the levels of IL-1 $\beta$, IL- 6 and TNF- $\alpha$. To further verify the anti-inflammatory effects of Fag, an LPS-stimulated murine macrophage cell line was used. The results revealed that Fag significantly inhibited LPS-induced secretion of TNF- $\alpha$ and IL-6. Further experiments demonstrated that Fag inhibited the expression of proinflammatory cytokines via inhibiting the phosphorylation of IкB.

Compared with the conventional treatment for IBD, SASP, the incidence of side effects was significantly decreased with Fag treatment, whereas the therapeutic efficiency was similar. The results of the present study provide evidence that Fag may be a suitable alternative herbal medicine for the treatment of IBD in clinical practice, although identifying the optimal dosage requires further investigation.

In conclusion, the present study demonstrates that the ethanol extract of Fag exerts protective effects in TNBSinduced colitis mice via its anti-inflammatory action. These results indicate that Fag may be an effective therapeutic treatment for IBD.

\section{Acknowledgements}

The present study was supported by the Specialized Research Fund for the Doctoral Program of Higher Education (grant no. 20133237110008), the National Natural Science Funds of China (grant no. 81503536), the Natural Science Foundation of Jiangsu Province (grant nos. BK20151567, BK20151008 and BK20140959), the Jiangsu Provincial Bureau of Traditional Chinese Medicine (grant no. YB2017066), the Natural Science Foundation of Universities in Jiangsu Province (grant no. 15KJB360008) and the Key Subject of Zhoupu Hospital, Pudong New Area, Shanghai (grant no. zp-xk-2015b-5).

\section{References}

1. Lutgens M, OijenM, van Mooiweer E, van der Valk M, Vleggaar F, Siersema P and Oldenburg B: A risk-profiling approach for surveillance of inflammatory bowel disease-colorectal carcinoma is more cost-effective: A comparative cost-effectiveness analysis between international guidelines. Gastrointest Endosc 80: 842-848, 2014.

2. Rubin DT: Why it's time for updated U.S. colorectal cancer prevention guidelines in inflammatory bowel disease. Gastrointest Endose 80: 849-851, 2014.

3. Huttenhower C, Kostic AD and Xavier RJ: Inflammatory bowel disease as a model for translating the microbiome. Immunity 40: 843-854, 2014

4. Tsai SY, Yang TY, Lin CL, Tsai YH, Kuo CF and $\mathrm{Kao} \mathrm{CH}$ Increased risk of varicella zoster virus infection in inflammatory bowel disease in an Asian population: A nationwide population-based cohort study. Int J Clin Pract 69: 228-234, 2015.

5. Paul S, Wand M, Emerick GT and Richter JM: The role of latanoprost in an inflammatory bowel disease flare. Gastroenterol Rep (Oxf) 2: 232-234, 2014.

6. Deepak P and Stobaugh DJ: Maternal and foetal adverse events with tumour necrosis factor-alpha inhibitors in inflammatory bowel disease. Aliment Pharm Therap 40: 1035-1043, 2014.

7. Ghouri YA, Richards DM, Rahimi EF, Krill JT, Jelinek KA and DuPont AW: Systematic review of randomized controlled trials of probiotics, prebiotics and synbiotics in inflammatory bowel disease. Clin Exp Gastroenterol 7: 473-487, 2014.

8. Kang A, Zhang S, Shan J and Di L: Gut microbiota-mediated deglycosylation of ginsenoside $\mathrm{Rb}-1$ in rats: In vitro and in vivo insights from quantitative ultra-performance liquid chromatography-mass spectrometry analysis. Anal Methods 7: 6173-6181, 2015 .
9. Heilmann RM, Otoni CC, Jergens AE, Grutzner N, Suchodolski JS and Steiner JM: Systemic levels of the anti-inflammatory decoy receptor soluble RAGE (receptor for advanced glycation end products) are decreased in dogs with inflammatory bowel disease. Vet Immunol Immunopathol 161: 184-192, 2014.

10. Shouval DS, Ebens CL, Murchie R, McCann K, Rabah R, Klein C, Muise A, and Snapper SB: Large b-cell lymphoma in an adolescent patient with IL-10 receptor deficiency and history of infantile inflammatory bowel disease. J Pediatr Gastroenterol Nutr 63: e15-e17, 2016.

11. Hyams JS: Standardized recording of parameters related to the natural history of inflammatory bowel disease: From Montreal to Paris. Dig Dis 32: 337-344, 2014.

12. Zhang Y, Wang Y, Zhang F, Wang K, Liu G, Yang M, Luan Y, Zhao Z, Zhang J, Cao X and Zhang D: Allyl methyl disulfide inhibits IL-8 and IP-10 secretion in intestinal epithelial cells via the NF-KB signaling pathway. Int Immunopharmacol 27: 156-163, 2015

13. Nishitani Y, Yamamoto K, Yoshida M, Azuma T, Kanazawa K, Hashimoto $\mathrm{T}$ and Mizuno M: Intestinal anti-inflammatory activity of luteolin: Role of the aglycone in NF- $\kappa \mathrm{B}$ inactivation in macrophages co-cultured with intestinal epithelial cells. Biofactors 39: 522-533, 2013.

14. Liu J, Zhou F, Chen Q, Kang A, Lu M, Liu W, Zang X, Wang G and Zhang J: Chronic inflammation up-regulates P-gp in peripheral mononuclear blood cells via the STAT3/Nf-kb pathway in 2,4,6-trinitrobenzene sulfonic acid-induced colitis mice. Sci Rep 5: 13558, 2015.

15. Freeman JJ, Rabah R, Hirschl RB, Maspons A, Meier D and Teitelbaum DH: Anti-TNF- $\alpha$ treatment for post-anastomotic ulcers and inflammatory bowel disease with Crohn's-like pathologic changes following intestinal surgery in pediatric patients. Pediatr Surg Int 31: 77-82, 2015.

16. Loftus EJ: Biologic therapy in inflammatory bowel disease. Gastroenterol Clin North Am 43: xv-xvii, 2014.

17. Dave M, Papadakis KA and Faubion WA Jr: Immunology of inflammatory bowel disease and molecular targets for biologics. Gastroenterol Clin North Am 43: 405-424, 2014.

18. Maranville JC, Micic D, Hanauer SB, Rienzo AD and Kupfer SS: In vitro sensitivity assays and clinical response to glucocorticoids in patients with inflammatory bowel disease. J Crohns Colitis 8: 1539-1547, 2014.

19. Bishop JB, Witt KL, Gulati DK and MacGregor JT: Evaluation of the mutagenicity of the anti-inflammatory drug salicylazosulfapyridine (SASP). Mutagenesis 5: 549-554, 1990.

20. Tian L, Xu L and Yang S: Chemical composition of Fagopyrum cymosum (Trev.) Meisn. Zhongguo Zhong Yao Za Zhi 22: 743-765, 1997 (In Chinese).

21. Dong LY, Wang CY, Wu CQ, Jiang Q and Zhang ZF: Protection and mechanism of Fagopyrum cymosum on lung injury in rats with Klebsiella pneumonia. Zhong Yao Cai 35: 603-607, 2012 (In Chinese).

22. Chan PK: Inhibition of tumor growth in vitro by the extract of Fagopyrum cymosum (fago-c). Life Sci 72: 1851-1858, 2003.

23. Shen L, Wang P, Guo J and Du G: Anti-arthritic activity of ethanol extract of Fagopyrum cymosum with adjuvant-induced arthritis in rats. Pharm Biol 51: 783-789, 2013.

24. Liu LN, Yan J and Sun ZG: Effect of Fagopyrum cymosum (Trev.) Meisn alcohol extract on defecation and isolated colon of diarrhea-IBS rats and its mechanism. Zhongguo Zhong Xi Yi Jie He Za Zhi 34: 1469-1475, 2014 (In Chinese).

25. Liu L, Cai X, Yan J, Luo Y, Shao M, Lu Y, Sun Z and Cao P: In Vivo and In Vitro Antinociceptive effect of Fagopyrum cymosum (Trev.) Meisn extracts: A possible action by recovering intestinal barrier dysfunction. Evid Based Complement Alternat Med 2012: 983801, 2012.

26. Shao M, Yang YH, Gao HY, Wu B, Wang LB and Wu LJ: Phenolic acid derivatives from the rhizome of Fagopyrum cymosum. Zhongguo Zhong Yao Za Zhi 30: 1591-1593, 2005 (In Chinese).

27. Witaicenis A, Luchini AC, Hiruma-Lima CA, Felisbino SL, Garrido-Mesa N, Utrilla P, Gálvez J and Di Stasi LC: Suppression of TNBS-induced colitis in rats by 4-methylesculetin, a natural coumarin: Comparison with prednisolone and sulphasalazine. Chem Biol Interact 195: 76-85, 2012.

28. Cui L, Feng L, Zhang ZH and Jia XB: The anti-inflammation effect of baicalin on experimental colitis through inhibiting TLR4/NF- $\kappa$ B pathway activation. Int Immunopharmacol 23: 294-303, 2014.

29. Livak KJ and Schmittgen TD: Analysis of relative gene expression data using real-time quantitative PCR and the 2(-Delta Delta C(T)) method. Methods 25: 402-408, 2001. 
30. te Velde AA, Verstege MI and Hommes DW: Critical appraisal of the current practice in murine TNBS-induced colitis. Inflamm Bowel Dis 12: 995-999, 2006.

31. Pastor RO, Lopez SR, Albéniz AE, Martínez AH, Sevillano ER and Martínez AA: Serum lipopolysaccharide-binding protein in endotoxemic patients with inflammatory bowel disease. Inflamm Bowel Dis 13: 269-277, 2007.

32. Guandalini S: Are probiotics or prebiotics useful in pediatric irritable bowel syndrome or inflammatory bowel disease? Front Med (Lausanne) 1: 23, 2014.

33. Choi EY, Jin JY, Choi JI, Choi IS and Kim SJ: Effects of luteolin on the release of nitric oxide and interleukin- 6 by macrophages stimulated with lipopolysaccharide from Prevotella intermedia. J Periodontol 82: 1509-1517, 2011.

34. Yang CP, Huang GJ, Huang HC, Chen YC, Chang CI, Wang SY, Chang HS, Tseng YH, Chien SC and Kuo YH: The effect of the aerial part of Lindera akoensis on lipopolysaccharides (LPS)-induced nitric oxide production in RAW264.7 cells. Int J Mol Sci 14: 9168-9181, 2013.

35. Funakoshi T, Yamashita K, Ichikawa N, Fukai M, Suzuki T, Goto R, Oura T, Kobayashi N, Katsurada T, Ichihara S, et al: A novel NF- $\kappa$ B inhibitor, dehydroxymethylepoxyquinomicin, ameliorates inflammatory colonic injury in mice. J Crohns Colitis 6: 215-225, 2012.

36. Hardee S, Alper A, Pashankar DS and Morotti RA Histopathology of duodenal mucosal lesions in pediatric patients with inflammatory bowel disease: Statistical analysis to identify distinctive features. Pediatr Dev Pathol 17: 450-454, 2014.
37. Beniwal-Patel $\mathrm{P}$ and Saha $\mathrm{S}$ : The role of integrin antagonists in the treatment of inflammatory bowel disease. Expert Opin Biol Ther 14: 1815-1823, 2014.

38. Munakata S, Tashiro Y, Nishida C, Sato A, Komiyama H, Shimazu H, Dhahri D, Salama Y, Eiamboonsert S, Takeda K, et al: Inhibition of plasmin protects against colitis in mice by suppressing matrix metalloproteinase 9-mediated cytokine release from myeloid cells. Gastroenterology 148: 565-578, 2015.

39. Castro J, Ocampo Y and Franco L: Cape gooseberry (Physalis peruviana $\mathrm{L}$.) calyces ameliorate TNBS acid-induced colitis in rats. J Crohns Colitis 9: 1004-1015, 2015.

40. Fischer A, Gluth M, Weege F, Pape UF, Wiedenmann B, Baumgart DC and Theuring F: Glucocorticoids regulate barrier function and claudin expression in intestinal epithelial cells via MKP-1. Am J Physiol Gastrointest Liver Physiol 306: G218-G228, 2014.

41. Li X, Wang Q, Xu H, Tao L, Lu J, Cai L and Wang C: Somatostatin regulates tight junction proteins expression in colitis mice. Int J Clin Exp Pathol 7: 2153-2162, 2014.

42. Hering NA and Schulzke JD: Therapeutic options to modulate barrier defects in inflammatory bowel disease. Dig Dis 27: 450-454, 2009. 